\title{
A Non-invasive, Easy to Use Medical Device for Arterial Stiffness
}

\author{
IULIUS J UGANARUㄹ, CONSTANTIN TUDOR LUCA², ANDREEA-IULIA DOBRESCU1*, OANA VOINESCU, MARIA PUIU1, \\ SIMONA FARCAS ${ }^{1 *}$, NICOLETA ANDREESCU ${ }^{1}$, MIRCEA IURCIUC ${ }^{3}$ \\ ${ }^{1}$ Victor Babes University of Medicine and Pharmacy, Department of Genetics, 2 Eftimie Murgu Sq., 300041, Timisoara, Romania \\ 2 Victor Babes University of Medicine and Pharmacy, Cardiology Department, 2 Eftimie Murgu Sq., 300041, Timisoara, Romania \\ ${ }^{3}$ Victor Babes University of Medicine and Pharmacy, Department of Preventive Medicine, Angiogenesis Research Center, 2 \\ Eftimie Murgu Sq., 300041, Timisoara, Romania
}

\begin{abstract}
Arterial stiffness is classified as a useful marker of early vascular damaging and a predictor of cardiovascular events in young people. We aimed to present the efficacy of a non invasive device in cardiovascular diseases prevention. Using the Arteriograph device, it was performed a cross sectional, non-invasive study in 313 healthy students. Non-invasive screening of apparently healthy young subjects with high WTH ratio values may be beneficial for detecting early, asymptomatic arterial atherosclerosis.
\end{abstract}

Keywords: arterial stiffness, cardio-vascular risk, prevention, arteriograph

Atherosclerotic cardiovascular disease remains the primary cause of severe disability and death all over the world although major risk factors are known and effective treatment exists [1]. Each minute, more than one person worldwide dies from heart disease [2]. Symptoms of cardiovascular (CV) disease leading to heart attacks and strokes usually appear only in late stages, that is why arterial disease remains unknown through most of its evolution stages. Still, atherosclerosis is preventable, the more it is discovered in early stages $[3,4]$.

Traditional cardiovascular risk factors (obesity, smoking, age, gender, hypertension, diabetes, cholesterol, genetics) are well known and several national programs are initiated to prevent or to reduce them. Abdominal obesity is considered a risk factor for cardiovascular disease (CVD). Compared to body mass index (BMI), anthropometric measures of abdominal obesity as waist-to-hip ratio (WHR), appear to be more strongly associated with metabolic risk factors [7] incident CVD events, and death [5]. WTH ratio is a better indicator for abdominal obesity due to its close connection with visceral fat has a stronger relation with CVD [6] and nevertheless it is quickly measurable and simple for interpretation. However, it is still not found in the traditional CV risk scores criteria.

Arteriosclerosis has also another risk marker, arterial stiffness, that brings information for the prediction of future cardiovascular events $[1,5]$. Affecting the larger central arterial system (the aortic system and its central branches), it is positively associated with systolic, heart failure, coronary artery disease, heart failure and atrial fibrillation. Several suggestive markers can predict vascular stiffening. Early identification and prevention is more effective compared with treatment [6].

Pulse wave velocity (PWV), a direct arterial stiffness marker, is considered as a 'gold standard' parameter, with the highest predictive value for cardiac events, according to the Current European guidelines recommendations [8]. PWV reveals the velocity of the movement of the pulse wave generated by left ventricle ejection. Augmentation index (Alx) is an indirect marker of arterial stiffness and a directmeasurement of the wave reflection, also confirmed to be associated with CV risk. Brachial augmentation index (Alx Brach) and aortic augmentation index (Alx Ao) are calculated as the difference between the amplitude of the late systolic and first systolic waves, divided by the pulse pressure and multiplied by 100. Central systolic blood pressure (SBPao), an indicator of central hemodynamics, is a complementary stiffness index, also used as a predictor of CV events [8].

The predictive value of arterial stiffness in CV diseases is well recognized and also its applicability in clinical practice. Years and years, several devices demonstrated to be efficient in CV markers evaluation and important studies evaluated their applicability. The vascular stiffness evaluation became entirely non-invasive, large used worldwide.

The aim of presented study is to highlight the clinical value of an innovative, easy to use and non invasive medical device in arterial stiffness prevention.

\section{Experimental part \\ Material and method}

This cross sectional study enrolled young healthy volunteers from Victor Babes University of Medicine and Pharmacy, Timisoara, Romania. The written consent was obtained from each student, after they had been informed about the aim and procedures of the study. All investigations were in accordance with the principles affirmed in the Declaration of Helsinki, and were approved by Victor Babes University ethics committee.

Any known disease or chronic medication (e.g. statins) represented exclusion criteria. Specialized cardiologists non-invasively evaluated students. The clinical evaluation included general medical consult and anthropometric parameters were measured. We calculated the body mass index (BMI) and WTH ratio according to the international criteria [9].

Arterial stiffness parameters were obtained using the Arteriograph (TensioMed Ltd., Budapest, Hungary), an innovative oscillometric device that evaluates important parameters of arterial stiffness [10]. The evaluation was performed in the morning, in a quiet room, with the participant lying down and resting 15 min before, without moving or speaking, according to the device instructions. The cuff was attached to the right upper arm of the subject. There was no food intake or smoking $3 \mathrm{~h}$ prior to the test; also no alcohol nor caffeine drinking was allowed $10 \mathrm{~h}$ before the examination. The same investigator evaluated all patients. The principle of this methods is based on plethysmography and the device records pulsatile pressure changes in a blood vessels (artery) [10]. As a first step, the Arteriograph measures the arterial blood pressure in the

\footnotetext{
* email: dobrescu.andreea.iulia@gmail.com, Phone: +40769663879; sfarcas2004@yahoo.com
} 
upper arm and generates a higher wave, compared with the measured systolic blood pressure. The pressure fluctuations are recorded and interpreted with specific software. Pulse wave velocity (PWV) is calculated between the beginning of the first wave and the beginning of the second one and it is expressed in $\mathrm{m} / \mathrm{s}$. The augmentation index (Alx) was calculated by the software in relation to the pulse pressure and itrepresent the pressure difference between the first and second wave. It is expressed in percentages. Aortic and brachial augmentation index were calculated (Alx Brach Alx Ao) [10]. Central blood pressure (SBPao) to each study volunteer were also measured, in 2 phases- systolic and diastolic (fig. 1). All measurements fulfilled quality control criteria. Obtained values were classified in accordance to the expert consensus recommendations on arterial stiffness [11].

Statistical analysis was performed using IBM SPSS Statistics 23 program and a two-tailed $p$ value $<0.05$ was considered significant. The obtained values are expressed in median and quartiles (they did not have normal distribution). We evaluated the entire cohort results and we also compared the results between women and males using independent samples t- test. Spearman's correlation coefficients were applied to establish the relation between variables obtained with the arteriography and anthropometric indices.

\section{Results and discussions}

Our study group involved 313 healthy medical students, 184 males and 129 females, aged between 18 to 53 years old. Table 1 described the evaluated subjects.

Males and females had the same median age (20 years). The female's group had a smaller median weight compared with males.

The group median for BMI was $25.1 \mathrm{~kg} / \mathrm{m}^{2}$ for males and $20.76 \mathrm{~kg} / \mathrm{m}^{2}$ for females, $\mathrm{p}$-value 0.002 . The calculated WTH ratio for male's group was 0.85 (median) and for female's 0.79 , p-value 0.015 .

\begin{tabular}{|c|c|c|c|c|c|c|c|c|c|}
\hline & \multicolumn{4}{|c|}{ Males } & \multicolumn{4}{|c|}{ Females } & \multirow{3}{*}{ p- value } \\
\hline & \multicolumn{4}{|c|}{184} & \multicolumn{4}{|c|}{129} & \\
\hline & Median & $25 \%$ & $50 \%$ & $75 \%$ & Median & $25 \%$ & $50 \%$ & $75 \%$ & \\
\hline Age (years) & 20 & 19 & 20 & 22 & 20 & 19 & 20 & 22 & \\
\hline $\begin{array}{l}\text { Height } \\
\text { (centimeter-cm }\end{array}$ & 176 & 173 & 176 & 180 & 164 & 159 & 164 & 167.5 & 0.895 \\
\hline $\begin{array}{l}\text { Weight } \\
\text { (kilograms- kg }\end{array}$ & 78 & 67 & 78 & 90 & 56 & 51 & 56 & 61 & $=0.001$ \\
\hline BMI $(\mathrm{kg} / \mathrm{m} 2)$ & 25.1 & 22.037 & 25.1 & 28.4 & 20.76 & 19.27 & 20.76 & 23.32 & 0.002 \\
\hline WTHr & 0.85 & 0.82 & 0.85 & 0.89 & 0.79 & 0.77 & 0.79 & 0.815 & 0.015 \\
\hline $\begin{array}{l}\text { AIx Brachial } \\
{[\%]}\end{array}$ & -64 & -70 & -64 & -56.8 & -50.5 & -57.05 & -50.5 & -39.15 & 0.037 \\
\hline $\begin{array}{l}\text { AIx Aortic } \\
{[\%]}\end{array}$ & 5.2 & 2.1 & 5.2 & 8.9 & 12.1 & 8.8 & 12.1 & 17.8 & 0.038 \\
\hline PWVao $[\mathrm{m} / \mathrm{s}]$ & 7.2 & 6.5 & 7.2 & 8.3 & 6.5 & 5.8 & 6.5 & 7.15 & $=0.001$ \\
\hline \multirow{4}{*}{$\mathrm{SBPao}[\mathrm{mmH}$} & Min & \multicolumn{3}{|c|}{81} & Min & \multicolumn{3}{|l|}{79} & \multirow{4}{*}{0.101} \\
\hline & Max & \multicolumn{3}{|c|}{140} & $\operatorname{Max}$ & \multicolumn{3}{|l|}{131} & \\
\hline & Mean & \multicolumn{3}{|c|}{111.424} & Mean & \multicolumn{3}{|c|}{103.109} & \\
\hline & $\begin{array}{l}\text { Std. } \\
\text { Deviation }\end{array}$ & \multicolumn{3}{|c|}{9.1505} & $\begin{array}{l}\text { Std. } \\
\text { Deviation }\end{array}$ & \multicolumn{3}{|l|}{10.592} & \\
\hline
\end{tabular}

Table 1

COHORT DESCRIPTION

The data did not had a normal distribution and they are presented using median and quartiles
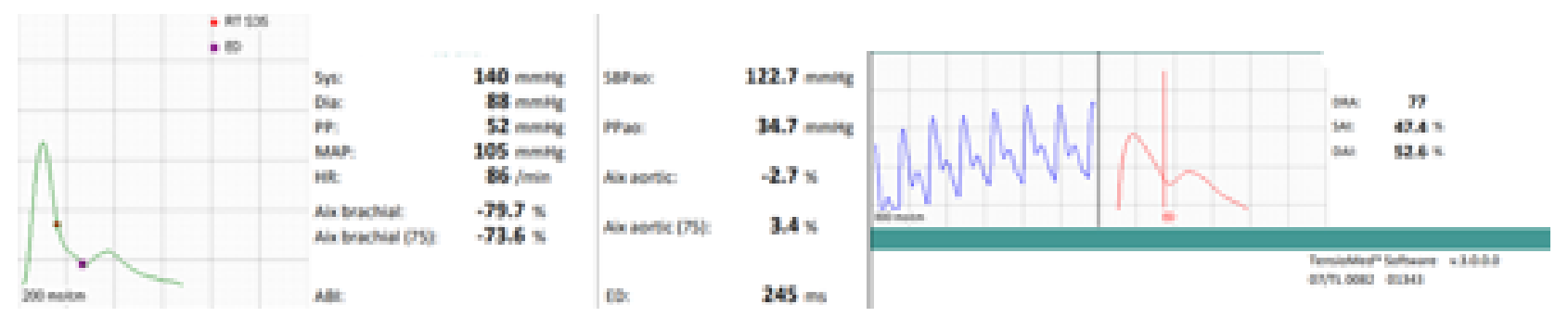

Fig. 1 Systolic and dyastolic blood pressure measurement in one patient 


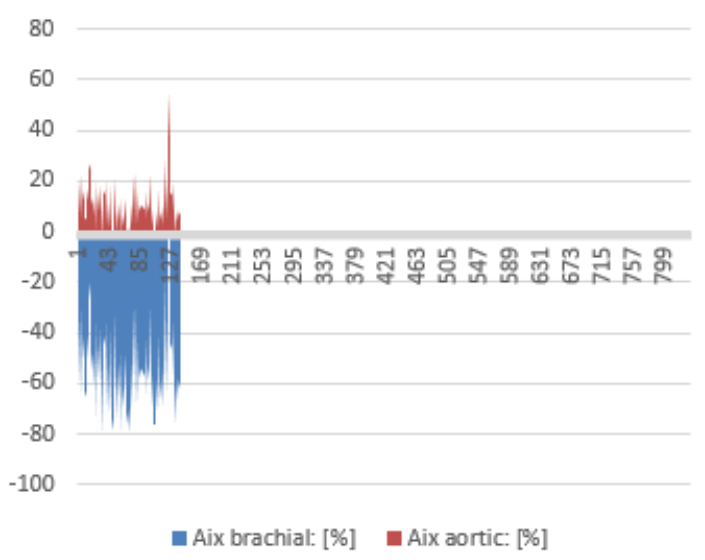

Fig. 2 Values of Alx Brachial and Alx Aortic

Table 2

SPEARMAN'S CORRELATION BETWEEN VARIABLES

\begin{tabular}{|l|l|l|l|l|l|l|l|l|l|}
\hline & & \multicolumn{2}{|c|}{ PWVao [m/s] } & \multicolumn{2}{c|}{ SBPao [mmHg] } & \multicolumn{2}{c|}{ AIx Aortic [\%] } & \multicolumn{2}{|c|}{ AIx Brachial [\%] } \\
\hline & Males & Females & Males & Females & Males & Females & Males & Females \\
$(\mathrm{n}=184)$ & $(\mathrm{n}=129)$ & $(\mathrm{n}=184)$ & $(\mathrm{n}=129)$ & $(\mathrm{n}=184)$ & $(\mathrm{n}=129)$ & $(\mathrm{n}=184)$ & $(\mathrm{n}=129)$ \\
\hline $\begin{array}{l}\text { WTH } \\
\text { Ratio }\end{array}$ & $\begin{array}{l}\text { Spearman's } \\
\text { rho }\end{array}$ & .241 & .237 & .233 & .339 & .089 & .140 & .089 & .141 \\
\hline & $\begin{array}{l}\text { Sig. (2- } \\
\text { tailed) }\end{array}$ & .001 & .007 & .001 & .000 & .231 & .113 & .230 & .111 \\
\hline
\end{tabular}

We noticed a high difference between Alx Brachial median values between the two groups ( $p$-value 0.037). All the obtained values from Aix Brachial and Aortic are illustrated in figure 2. For PWV (fig. 3), the difference between women's and male's group were also statistical significant; SBPao had very closed value between the 2 groups, with no signicant differences ( $p$-value 0.1).

The correlation between WTH ratio and SBPao was medium and positive in females. There also was a statistical significant low positive correlation between PW Nao and WTH ratio in male's and female's group (table 2).

The correlation between WTH ratio and Alx Aortic or Alx Brachial was negligible and without statistical significance. When we considered the entire cohort, the correlation between WTH ratio and SBPao was strong direct (Spearman's rho 0.454) and statistical significant $(p<0.001)$.

In this study, we emphasize the relationship between WTH ratio, a marker of abdominal obesity, and arterial function parameters in young healthy medical students, males and females. We choose to evaluate young healthy people because the incidence of cardiovascular events is high probably because of several risk factors- low medical prophylactic evaluations, unappropriated life style and fast food diet. Using an easy, non-invasive medical device, we evaluated the arterial stiffness of those subjects and we had the opportunity to identify patients at cardiovascular risk, before any clinical sign.

WTH ratio is a simple, objective index that can be easily and quickly measured and used to provide a simple and non-invasive approach in the evaluation of the arterial stiffness. Even in young adults, increased abdominal adiposity determines early vascular aging leading to cardiovascular complications. Studies concentrated on obese, middle aged population or elderly, emphasized the association between anthropometric measures, such as WTH ratio and arterial stiffness [ $[12,13]$. Nordstrand et al. showed that measures of both general obesity and abdominal obesity were associated with PWV in morbidly obese women, but not in men [12]. Rider et al. used magnetic resonance imaging to show that obesity is associated with increased PWV, and with subacute

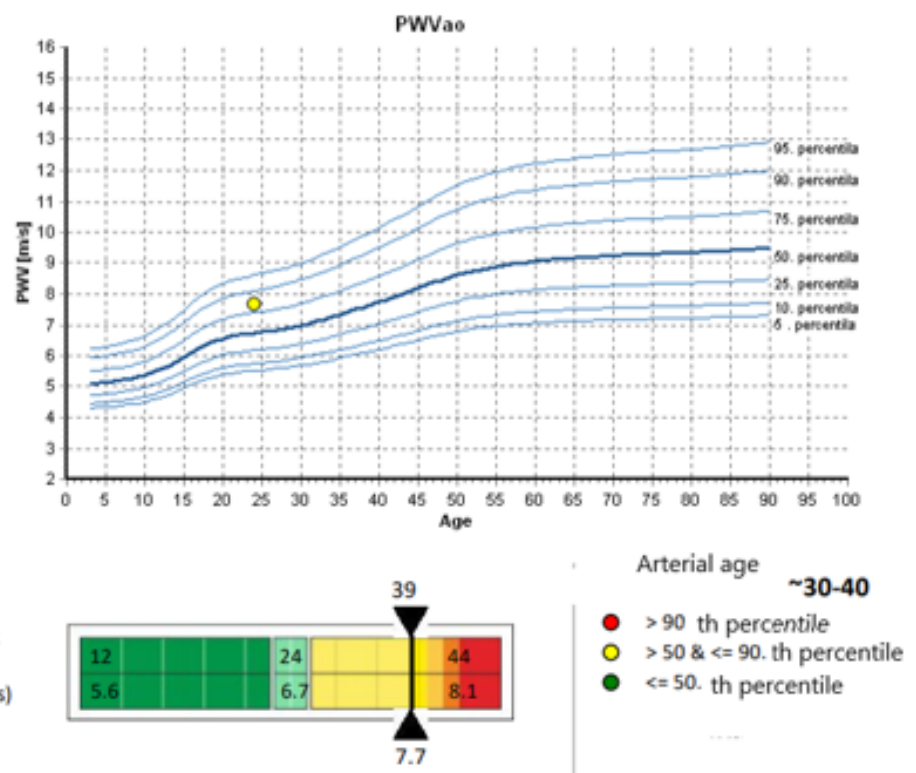

Fig. 3. PWVao measurement and arterial age estimation in one evaluated subjuct 
inflammation, and furthermore, with alterations in hormonal and metabolic profile. On the other hand, their study emphasized on showing that weight loss results in reduced PWV that can be related to improvements in metabolic and hormonal profile by reduction in visceral and subcutaneous fat mass [13]. There are also researches that have examined the relation between anthropometric indices and arterial stiffness in healthy young populations close to normal weight, but their results were inconsistent $[14,15]$. Wildman et al. [16] found that WTH ratio was strongly associated with pulse wave velocity (PWV), the direct marker of arterial stiffness. Van den Munckhebet et al found a significant correlation between WTH ratio and PWV only in men [17]. Maher et al. [18] show ed that none of the anthropometric measures was associated with augmentation indices. It is also important to emphasize that not all of these studies have taken into account sex differences.

Our results highlight the relation between WTH ratio and cardiovascular diseases, in young individuals. Even if the $\mathrm{BMI}$ is normal for age and sex, the abdominal fat storage could be considered a risk factor. WTH ratio is not indicated to be used in children but it was associated with an increased risk of early death in normal weight individuals [19].

\section{Conclusions}

The Arteriograph is a medical device with a proved efficiency. It offers the possibility to evaluate arterial stiffness parameters in a non-invasive, rapidly and reproducible way. It has several limitation especially related to technique. If the cuff is not well positioned (very tightly around the subject's arm and the arm absolutely motionless), there is a risk to have a false result. The interpretation is made by a specific software and the biases at this step are very low.

In presented study, the relevant correlation was for female group and that could be explain because the abdominal fat storage, abdominal obesity, is more frequent in females compared with males. WTH ratio is a common value, calculated by many of medical or non-medical devices, especially those from fitness centers. We used young healthy people because they went more often to fitness compared with prophylactic medical evaluation. We suggest that it could be indicated like an alarm when its value is higher than 0.8 for women, 0.95 for men as an important cardiovascular risk factor.

These findings reveal the importance of WTH ratio determination as a risk factor for arterial stiffening. Noninvasive screening of apparently healthy young subjects with high WTH ratio values may be beneficial for detecting early, asymptomatic arterial atherosclerosis. Prevention is the best attitude in order to reduce CV morbidity and mortality in young population.

\section{References}

1. SUTTON-TYRRELL K, NAJ J AR SS, BOUDREAU RM, VENKITACHALAM L, KUPELIAN V, SIMONSICK EM, HAVLIK R, LAKATTA EG, SPURGEON $H$, KRITCHEVSKY S, PAHOR M, BAUER D, NEWMAN A. Elevated aortic pulse wave velocity, a marker of arterial stiffness, predicts cardiovascular events in well-functioning older adults. Circulation 2005; 111: 3384-3390

2. HERON M. DEATHS: Leading causes for 2014. National vital statistics reports. 2016;65(5).
3. LAURENT S., COCKROFT J., VAN BORTEL L., BOUTOUYRIE P., GIANNATTASIO C., HAYOZ D., PANNIER B., VLACHOPOULOS C., WILKINSON I., STRUIJKER-BOUDIER H. Expert consensus document on arterial stiffness: Methodological issues and clinical applications. Eur. Heart J . 2006;27:2588-2605. doi: 10.1093/eurheartj/ehl254

4. LEHMANN ED. Clinical value of aortic pulse-wave velocity measurement. Lancet. 1999 Aug 14; 354(9178):528-9.

5. KANNEL WB, CUPPLES LA, RAMASWAMI R, STOKESJ 3RD, KREGER $B E$, HIGGINS M. Regional obesity and risk of cardiovascular disease; the Framingham Study. J Clin Epidemiol. 1991; 44(2):183-90.

6. MOLARIUS A, SEIDELL JC. Selection of anthropometric indicators for classification of abdominal fatness-a critical review. Int J Obes Relat Metab Disord. 1998; 22:719-727 Molarius A, Seidell JC. Selection of anthropometric indicators for classification of abdominal fatnessa critical review. Int J Obes Relat Metab Disord. 1998; 22:719-727.

7. VAN POPELE NM, GROBBEE DE, BOTS ML, ASMAR R, TOPOUCHIAN J, RENEMAN RS, HOEKS AP, VAN DER KUIP DA, HOFMAN A, WITTEMAN JC. Association between arterial stiffness and atherosclerosis: the Rotterdam Study. Stroke. 2001 Feb; 32(2):454-60.

8. SEIDELL JC, PERUSSE L, DESPRES J P, BOUCHARD C. Waist and hip circumferences have independent and opposite effects on cardiovascular disease risk factors: the Quebec Family Study. Am J Clin Nutr. 2001; 74:315-321.

9. HEYWARD VH, STOLARCYZK LM: Applied Bodie Composition Assessment. Champaign IL, Human Kinetics, 1996: p82.

10. BAULMANN J 1, SCHILLINGS U, RICKERT S, UEN S, DÜSING R, ILLYES M, CZIRAKI A, NICKERING G, MENGDEN T. A new oscillometric method for assessment of arterial stiffness: comparison with tonometric and piezo-electronic methods. J Hypertens. 2008 Mar;26(3):523-8. doi: 10.1097/HJ H.0b013e3282f314f7.

11. VAN BORTEL LM, LAURENT S, BOUTOUYRIE P, CHOWIENCZYK $P$, CRUICKSHANK JK, DE BACKER T, FILIPOVSKY J, HUYBRECHTS $S$, MATTACE-RASO FU, PROTOGEROU AD, SCHILLACI G, SEGERS P, VERMEERSCH S, WEBER T. Expert consensus document on the measurement of aortic stiffness in daily practice using carotid-femoral pulse wave velocity. J Hypertens 2012; 30: 445-448.

12. NORDSTRAND N, GJ EVESTAD E, DINH K, et al. The relationship between various measures of obesity and arterial stiffness in morbidly obese patients. BMC Cardiovasc Disord. 2011; 11:7.

13. RIDER OJ , TAYAL U, FRANCIS J M, et al. The effect of obesity and weight loss on aortic pulse wave velocity as assessed by magnetic resonance imaging. Obesity (Silver Spring) 2010; 18:2311-16.

14. VAN DEN MUNCKHOF ICL, HOLEWIJN S, DE GRAAF J, RUTTEN $J H W$. Sex differences in fat distribution influence the association between BMI and arterial stiffness. J Hypertens. 2017 J un; 35(6):12191225.

15. WYKRETOWICZ A, ADAMSKA K, GUZIK P, KRAUZE T, WYSOCKI $H$.Indices of vascular stiffness and wave reflection in relation to body mass index or body fat in healthy subjects. Clin Exp Pharmacol Physiol. 2007 Oct; 34(10):1005-9.

16. WILDMAN RP, MACKEY RH, BOSTOM A, et al. Measures of obesity are associated with vascular stiffness in young and older adults. Hypertension. 2003; 42:468-73. [PubMed]

17. VAN DEN MUNCKHOF ICL, HOLEWIJN S, DE GRAAF J, RUTTEN $J$ JW. Sex differences in fat distribution influence the association between BMI and arterial stiffness. J Hypertens. 2017 J un;35(6):12191225.

18. MAHER V, O'DOWD M, CAREY M, et al. Association of central obesity with early Carotid intima-media thickening is independent of that from other risk factors. Int J Obes (Lond) 2009;33:136-43.

19. SAHAKYAN KR, SOMERS VK, RODRIGUEZ-ESCUDERO J, et al. Normal-Weight Central Obesity: Implications for Total and Cardiovascular MortalityAnnals of Internal Medicine. Published online November 102015.

Manuscript received: 23.06 .2018 